\title{
Common fixed points for multivalued mappings in G-metric spaces with applications
}

\author{
Zead Mustafa $^{a}$, Muhammad Arshad ${ }^{\mathrm{b}}$, Sami Ullah Khan ${ }^{\mathrm{b}, \mathrm{c}}$, Jamshaid Ahmad ${ }^{\mathrm{d}}$, M. M. M. Jaradat ${ }^{\mathrm{a}, *}$ \\ ${ }^{a}$ Department of Mathematics, Statistics and Physics, Qatar University, Doha-Qatar. \\ ${ }^{b}$ Department of Mathematics, International Islamic University, H-10, Islamabad - 44000, Pakistan. \\ ${ }^{c}$ Department of Mathematics, Gomal University D. I. Khan, KPK, Pakistan. \\ ${ }^{d}$ Department of Mathematics, University of Jeddah, P. O. Box 80327, Jeddah 21589, Saudi Arabia.
}

Communicated by Y. J. Cho

\begin{abstract}
In this paper, we define new notions called $(\mathrm{g}-\mathrm{F})$ contractions and generalize Mizoguchi-Takahashi contractions for complete G-metric spaces and we establish some new coincidence points and common fixed point results. Our results unify and generalize various known comparable results from the current literature. An example and application are given to illustrate the usability of the main results. (c)2017 All rights reserved.
\end{abstract}

Keywords: G-metric space, fixed point, F-contraction, $(\mathrm{g}-\mathrm{F})$ contraction. 2010 MSC: 47H10, 54H25.

\section{Introduction}

In 1922, Banach established the most famous fundamental fixed point theorem (so-called the Banach contraction principle [6]) which has played an important role in various fields of applied mathematical analysis. Due to its importance and simplicity, several authors have obtained many interesting extensions and generalizations. From one hand, the contraction is extended. For instance, Ćirić [8] introduced quasi contraction, and obtained fixed point theorems which is a generalization of Banach contraction principle.

On the other hand, the study of metric spaces expressed the most important role to many fields both in pure and applied science such as biology, medicine, physics and computer science (see [2, 20-33] and references therein). Some generalizations of the notion of a metric space have been proposed by some authors, such as, rectangular metric spaces, semi metric spaces, pseudo metric spaces, probabilistic metric spaces, fuzzy metric spaces, quasi metric spaces, quasi semi metric spaces, D-metric spaces, cone metric spaces, and partial metric spaces (see [3, 9, 13, 27, 28, 30, 32]). Branciari [7] introduced the notion of a generalized metric space replacing the triangle inequality by a rectangular type inequality. Thereafter he extended Banach's contraction principle in such spaces.

\footnotetext{
${ }^{*}$ Corresponding author

Email addresses: zead@qu.edu .qa (Zead Mustafa), marshadzia@iiu.edu.pk (Muhammad Arshad), gomal85@gmail.com (Sami Ullah Khan), jamshaid_jasim@yahoo.com (Jamshaid Ahmad), mmjst4@qu.edu.qa (M. M. M. Jaradat)

doi:10.22436/jnsa.010.05.23
} 
Mustafa and Sims [25] introduced the G-metric spaces as a generalization of the notion of metric spaces. They obtained some fixed point theorems for mappings satisfying different contractive conditions for more fixed point results on G-metric space (see [2, 22-25, 31]). Wardowski [35] introduced a new contraction called F-contraction and proved a fixed point result as a generalization of Banach contraction principle. Abbas et al. [1] further generalized the concept of F-contraction and proved certain fixed and common fixed point results. Over the years, Banach contraction principle has been generalized in different directions by several mathematicians (see [4-19, 21, 25]).

The aim of this paper is to define two new notions like $(\mathrm{g}-\mathrm{F})$ contractions and generalize MizoguchiTakahashi contractions for complete G-metric spaces and to establishes some new coincidence points and common fixed point theorems. Our results generalize various results of literature.

\section{Definitions and relevant results}

In this section, we present some definitions and results.

Definition 2.1 ([25]). Let $X$ be a nonempty set and $G: X \times X \times X \rightarrow \mathbb{R}^{+}$be a function satisfying the following properties

(G1) $G(x, y, z)=0$ if $x=y=z$;

(G2) $0<\mathrm{G}(x, x, y)$ for all $x, y \in X$ with $x \neq y$;

(G3) $G(x, x, y) \leqslant G(x, y, z)$ for all $x, y, z \in X$ with $y \neq z$;

(G4) $G(x, y, z)=G(x, z, y)=G(y, z, x)=\cdots$ (symmetry in all three variables);

(G5) $G(x, y, z) \leqslant G(x, a, a)+G(a, y, z)$ for all $x, y, z, a \in X$ (rectangle inequality).

Then, the function $G$ is called a generalized metric, or, a $G$-metric on $X$, and the pair $(X, G)$ is called a G-metric space.

Definition 2.2 ([25]). Let (X, G) be a G-metric space, and let $\left\{x_{n}\right\}$ be a sequence of points of $X$. Then, we say that $\left(x_{n}\right)$ is $G$-convergent to $x \in X$ if $\lim _{n, m \rightarrow \infty} G\left(x, x_{n}, x_{m}\right)=0$, that is, for any $\epsilon>0$, there exists $N \in \mathbb{N}$ such that $G\left(x, x_{n}, x_{m}\right)<\epsilon$ for all $n, m \geqslant N$. We call $x$ the limit of the sequence and write $x_{n} \rightarrow x$ or $\lim _{n \rightarrow \infty} x_{n}=x$.

Proposition 2.3 ([25]). Let (X, G) be a G-metric space. The following statements are equivalent:

(1) $\left(x_{n}\right)$ is $\mathrm{G}$-convergent to $\mathrm{x}$;

(2) $\mathrm{G}\left(\mathrm{x}_{\mathrm{n}}, \mathrm{x}_{\mathrm{n}}, \mathrm{x}\right) \rightarrow 0$ as $\mathrm{n} \rightarrow+\infty$;

(3) $\mathrm{G}\left(\mathrm{x}_{\mathrm{n}}, \mathrm{x}, \mathrm{x}\right) \rightarrow 0$ as $\mathrm{n} \rightarrow+\infty$;

(4) $\mathrm{G}\left(\mathrm{x}_{\mathrm{n}}, \mathrm{x}_{\mathrm{m}}, \mathrm{x}\right) \rightarrow 0$ as $\mathrm{n}, \mathrm{m} \rightarrow+\infty$.

Definition 2.4 ([25]). Let $(X, G)$ be a G-metric space. A sequence $\left\{x_{n}\right\}$ is called a G-Cauchy sequence if for any $\epsilon>0$, there is $N \in \mathbb{N}$ such that $G\left(x_{n}, x_{m}, x_{l}\right)<\epsilon$ for all $n, m, l \geqslant N$, that is $G\left(x_{n}, x_{m}, x_{l}\right) \rightarrow 0$ as $n$, $\mathrm{m}, \mathrm{l} \rightarrow+\infty$.

Definition $2.5([25])$. A G-metric space $(X, G)$ is called G-complete if every G-Cauchy sequence is Gconvergent in $(X, G)$.

It is worth mentioning that every $G$-metric on $X$ defines a metric $d_{G}$ on $X$ given by

$$
d_{G}(x, y)=G(x, y, y)+G(y, x, x) \text { for all } x, y \in X .
$$

Example 2.6 ([25]). Let $(X, d)$ be a metric space. The function $G: X \times X \times X \rightarrow[0,+\infty)$, defined by

$$
G(x, y, z)=\max \{d(x, y), d(y, z), d(z, x)\}
$$

or

$$
G(x, y, z)=d(x, y)+d(y, z)+d(z, x)
$$

for all $x, y, z \in X$, is a G-metric on $X$. 
Corollary 2.7 ([25]). Let $(\mathrm{X}, \mathrm{d})$ be a metric space. Then $(\mathrm{X}, \mathrm{d})$ is complete metric space iff $(\mathrm{X}, \mathrm{G})$ is complete G-metric space.

Corollary 2.8 ([25]). A G-metric space (X, G) is continuous on its three variables.

Recently, Kaewcharoen et al. [19] introduced the following concepts. Let $X$ be a G-metric space. We shall denote $\mathrm{CB}(\mathrm{X})$ the family of all non-empty closed bounded subsets of $X$. Let $\mathrm{H}_{\mathrm{G}}(\cdot, \cdot, \cdot$,$) be the$ Hausdorff $G$-distance on $C B(X)$, that is for $A, B, C \in C B(X)$ we have

$$
H_{G}(A, B, C)=\max \left\{\sup _{x \in A} G(x, B, C) \sup _{x \in B} G(x, C, A), \sup _{x \in C} G(x, A, B)\right\}
$$

where

$$
\begin{aligned}
G(x, B, C) & =d_{G}(x, B)+d_{G}(B, C)+d_{G}(x, C), \\
d_{G}(x, B) & =\inf \left\{d_{G}(x, y), y \in B\right\}, \\
d_{G}(A, B) & =\inf \left\{d_{G}(a, b), a \in A, b \in B\right\} .
\end{aligned}
$$

Recall that $G(x, y, C)=\inf \{G(x, y, z), z \in C\}$. A mapping $f: X \longrightarrow 2^{X}$ is called a multi-valued mapping. A point $x \in X$ is called a fixed point of $f$ if $x \in f x$.

Lemma 2.9 ([34]). Let $(X, G)$ be a $G$-metric space and $A, B \in C B(X)$. Then for each $a \in A$, we have

$$
\mathrm{G}(\mathrm{a}, \mathrm{B}, \mathrm{B}) \leqslant \mathrm{H}_{\mathrm{G}}(\mathrm{A}, \mathrm{B}, \mathrm{B}) \text {. }
$$

Lemma 2.10 ([34]). Let $(\mathrm{X}, \mathrm{G})$ be a $\mathrm{G}$-metric space. If $\mathrm{A}, \mathrm{B} \in \mathrm{CB}(\mathrm{X})$ and $\mathrm{a} \in \mathrm{A}$, then for each $\varepsilon>0$, there exists $\mathrm{b} \in \mathrm{B}$ such that

$$
G(a, b, b) \leqslant H_{G}(A, B, B)+\epsilon .
$$

Definition 2.11. Let $X$ be a non-empty set. Assume that $g: X \longrightarrow X$ and $f: X \longrightarrow 2^{X}$ are two mappings. If $w=g x \in f x$ for some $x \in X$, then $x$ is called a coincidence point of $g$ and $f$ and $w$ is a point of coincidence of $g$ and $f$. The mappings $g$ and $f$ are called weakly compatible if $g x \in f x$ for some $x \in X$ implies $g f(x) \subseteq f g(x)$.

Proposition 2.12 ([19]). Let $\mathrm{X}$ be a given non-empty set. Assume that $\mathrm{g}: \mathrm{X} \longrightarrow \mathrm{X}$ and $\mathrm{f}: \mathrm{X} \longrightarrow 2^{\mathrm{X}}$ are weakly compatible mappings. If $\mathrm{g}$ and $\mathrm{f}$ have a unique point of coincidence $\mathrm{w}=\mathrm{gx} \in \mathrm{fx}$, then $w$ is the unique common fixed point of $\mathrm{g}$ and $\mathrm{f}$.

In 2012, Wardowski [35] defined the F-contraction as follows.

Definition 2.13 ([35]). Let $(X, d)$ be a complete metric space. A mapping $T: X \rightarrow X$ is said to be an F-contraction if there exists $\tau>0$ such that

$$
\forall x, y \in X, d(T x, T y)>0 \Rightarrow \tau+F(d(T x, T y)) \leqslant F(d(x, y))
$$

where $F: \mathbb{R}_{+} \rightarrow \mathbb{R}$ is a mapping satisfying the following conditions:

(F1) $F$ is strictly increasing, i.e., for all $x, y \in \mathbb{R}_{+}$such that $x<y, F(x)<F(y)$;

(F2) for each sequence $\left\{\alpha_{n}\right\}_{n=1}^{\infty}$ of positive numbers, $\lim _{n \rightarrow \infty} \alpha_{n}=0$ if and only if $\lim _{n \rightarrow \infty} F\left(\alpha_{n}\right)=-\infty$;

(F3) there exists $k \in(0,1)$ such that $\lim _{\alpha \rightarrow 0^{+}} \alpha^{k} F(\alpha)=0$.

We denote by $\mathcal{F}$ the family of all functions $F$ that satisfy the conditions (F1)-(F3).

Remark 2.14. From (F1) and (2.1) it is easy to conclude that every F-contraction mapping $\mathrm{T}$ is necessarily continuous.

Theorem 2.15 ([35]). Let $(\mathrm{X}, \mathrm{d})$ be a complete metric space and $\mathrm{T}: \mathrm{X} \rightarrow \mathrm{X}$ be a F-contraction, then we have

(1) Thas a unique fixed point $x^{*} \in X$;

(2) for all $x \in X$, the sequence $\left\{T^{n} x\right\}$ is convergent to $x^{*}$. 


\section{Main results}

We start this section with the definition of $(\mathrm{g}-\mathrm{F})$ contraction and the main result of this section.

Definition 3.1. Let $(X, G)$ be a G-metric space. Let $T: X \longrightarrow C B(X)$ and $g: X \longrightarrow X$ be two mappings. Then the mapping $T$ is said to be $(g-F)$ contraction if there exist some $F \in \mathcal{F}$ and a constant $\tau>0$ such that

$$
H_{G}(T x, T y, T z)>0 \Longrightarrow 2 \tau+F\left(H_{G}(T x, T y, T z)\right) \leqslant F(G(g x, g y, g z))
$$

for all $x, y, z \in X$.

Theorem 3.2. Let $(\mathrm{X}, \mathrm{G})$ be a $\mathrm{G}$-metric space. Let $\mathrm{g}: \mathrm{X} \longrightarrow \mathrm{X}$ and $\mathrm{T}: \mathrm{X} \longrightarrow \mathrm{CB}(\mathrm{X})$ be a $(\mathrm{g}-\mathrm{F})$ contraction. If for any $\mathrm{x} \in \mathrm{X}, \mathrm{T} \mathrm{x} \subseteq \mathrm{g}(\mathrm{X})$ and $\mathrm{g}(\mathrm{X})$ is a $\mathrm{G}$-complete subspace of $\mathrm{X}$, then $\mathrm{g}$ and $\mathrm{T}$ have a point of coincidence in $\mathrm{X}$. Furthermore, if we assume that $\mathrm{gp} \in \mathrm{Tp}$ and $\mathrm{gq} \in \mathrm{Tq}$ implies $\mathrm{G}(\mathrm{gq}, \mathrm{gp}, \mathrm{gp}) \leqslant \mathrm{H}_{\mathrm{G}}(\mathrm{Tq}, \mathrm{Tp}, \mathrm{Tp})$, then

(i) $g$ and $\mathrm{T}$ have a unique point of coincidence;

(ii) if in addition $\mathrm{g}$ and $\mathrm{T}$ are weakly compatible, then $\mathrm{g}$ and $\mathrm{T}$ have a unique common fixed point.

Proof. Let $x_{0}$ be an arbitrary point of $X$. Since the range of $g$ contains the range of $T$, there exists a point $x_{1}$ in $X$ such that $g x_{1} \in T x_{0}$. If $g x_{1}=g x_{0}$, then $x_{0}$ is a coincidence point of $g$ and $T$ and the proof is complete, so we assume that $g x_{0} \neq g x_{1}$. Also if $T x_{0}=T x_{1}$, then $x_{1}$ is a coincidence point of $g$ and $T$. So we assume that $T x_{0} \neq T x_{1}$, which implies that $H_{G}\left(T x_{0}, T x_{1}, T x_{1}\right)>0$. Now from (3.1) we have

$$
2 \tau+F\left(H_{G}\left(T x_{0}, T x_{1}, T x_{1}\right)\right) \leqslant F\left(G\left(g x_{0}, g x_{1}, g x_{1}\right)\right) .
$$

Since $F$ is continuous from the right, there exists a real number $h>1$ such that

$$
\mathrm{F}\left(\mathrm{hH} \mathrm{H}_{\mathrm{G}}\left(T x_{0}, T x_{1}, T x_{1}\right)\right)<\mathrm{F}\left(\mathrm{H}_{\mathrm{G}}\left(T x_{0}, T x_{1}, T x_{1}\right)\right)+\tau \text {. }
$$

As $\mathrm{gx}_{1} \in \mathrm{T} \mathrm{x}_{0}$, so by Lemma 2.9, we have

$$
\mathrm{G}\left(\mathrm{gx_{1 }}, \mathrm{Tx_{1 }}, \mathrm{Tx_{1 }}\right) \leqslant \mathrm{H}_{\mathrm{G}}\left(T x_{0}, T x_{1}, T x_{1}\right)<h \mathrm{H}_{\mathrm{G}}\left(T x_{0}, T x_{1}, T x_{1}\right),
$$

where $h>1$. Now from $G\left(g x_{1}, T x_{1}, T x_{1}\right)<h H_{G}\left(T x_{0}, T x_{1}, T x_{1}\right)$ and Lemma 2.10 we deduce that there exists $x_{2} \in X$ with $g x_{2} \in T x_{1}$ such that

$$
\mathrm{G}\left(g x_{1}, g x_{2}, g x_{2}\right) \leqslant h H_{G}\left(T x_{0}, T x_{1}, T x_{1}\right) .
$$

Consequently, we get

$$
F\left(G\left(g x_{1}, g x_{2}, g x_{2}\right)\right) \leqslant F\left(h H_{G}\left(T x_{0}, T x_{1}, T x_{1}\right)\right)<F\left(H_{G}\left(T x_{0}, T x_{1}, T x_{1}\right)\right)+\tau,
$$

which implies that

$$
2 \tau+F\left(G\left(g x_{1}, g x_{2}, g x_{2}\right)\right) \leqslant 2 \tau+F\left(H_{G}\left(T x_{0}, T x_{1}, T x_{1}\right)\right)+\tau \leqslant F\left(G\left(g x_{0}, g x_{1}, g x_{1}\right)\right)+\tau .
$$

Thus

$$
\tau+\mathrm{F}\left(\mathrm{G}\left(g \mathrm{gx}_{1}, g \mathrm{x}_{2}, g \mathrm{x}_{2}\right)\right) \leqslant \mathrm{F}\left(\mathrm{G}\left(g \mathrm{x}_{0}, g \mathrm{x}_{1}, g \mathrm{x}_{1}\right)\right) .
$$

Continuing in this process, we can define a sequence $\left\{g x_{n}\right\} \subset X$ such that $g x_{n+1} \in T x_{n}$ with $g x_{n} \neq$ $g x_{n+1}, T x_{n} \neq T x_{n+1}$, and

$$
\tau+F\left(G\left(g x_{n}, g x_{n+1}, g x_{n+1}\right)\right) \leqslant F\left(G\left(g x_{n-1}, g x_{n}, g x_{n}\right)\right)
$$

for all $n \in \mathbb{N} \cup\{0\}$. Therefore

$$
\begin{aligned}
F\left(G\left(g x_{n}, g x_{n+1}, g x_{n+1}\right)\right) & \leqslant F\left(G\left(g x_{n-1}, g x_{n}, g x_{n}\right)\right)-\tau \\
& \leqslant F\left(G\left(g x_{n-2}, g x_{n-1}, g x_{n-1}\right)\right)-2 \tau \\
& \vdots \\
& \leqslant F\left(G\left(g x_{0}, g x_{1}, g x_{1}\right)\right)-n \tau
\end{aligned}
$$

for all $n \in \mathbb{N}$. Since $F \in \mathcal{F}$, by taking the limit as $n \longrightarrow \infty$ in (3.2) we have 


$$
\lim _{n \longrightarrow \infty} F\left(G\left(g x_{n}, g x_{n+1}, g x_{n+1}\right)\right)=-\infty \text {. Therefore by (F2) } \lim _{n \rightarrow \infty} G\left(g x_{n}, g x_{n+1}, g x_{n+1}\right)=0 .
$$

Now from (F3), there exists $0<k<1$ such that

$$
\lim _{n \rightarrow \infty}\left[G\left(g x_{n}, g x_{n+1}, g x_{n+1}\right)\right]^{k} F\left(G\left(g x_{n}, g x_{n+1}, g x_{n+1}\right)\right)=0 .
$$

By (3.2), we have

$$
\begin{aligned}
& {\left[G\left(g x_{n}, g x_{n+1}, g x_{n+1}\right)\right]^{k} F\left(G\left(g x_{n}, g x_{n+1}, g x_{n+1}\right)\right)-\left[G\left(g x_{n}, g x_{n+1}, g x_{n+1}\right)\right]^{k} F\left(G\left(g x_{0}, g x_{1}, g x_{1}\right)\right)} \\
& \quad \leqslant\left[G\left(g x_{n}, g x_{n+1}, g x_{n+1}\right)\right]^{k}\left[F\left(G\left(g x_{0}, g x_{1}, g x_{1}\right)\right)-n \tau-F\left(G\left(g x_{0}, g x_{1}, g x_{1}\right)\right)\right] \\
& \quad=-n \tau\left[G\left(g x_{n}, g x_{n+1}, g x_{n+1}\right)\right]^{k} \leqslant 0 .
\end{aligned}
$$

Therefore,

$$
\begin{aligned}
& {\left[G\left(g x_{n}, g x_{n+1}, g x_{n+1}\right)\right]^{k} F\left(G\left(g x_{n}, g x_{n+1}, g x_{n+1}\right)\right)+n \tau\left[G\left(g x_{n}, g x_{n+1}, g x_{n+1}\right)\right]^{k}} \\
& \quad \leqslant\left[G\left(g x_{n}, g x_{n+1}, g x_{n+1}\right)\right]^{k} F\left(G\left(g x_{0}, g x_{1}, g x_{1}\right)\right) .
\end{aligned}
$$

By taking the limit as $n \longrightarrow \infty$ in (3.5) and applying (3.3) and (3.4), we have

$$
\lim _{n \rightarrow \infty} n\left[G\left(g x_{n}, g x_{n+1}, g x_{n+1}\right)\right]^{k}=0 .
$$

It follows from (3.6) that there exists $n_{1} \in N$ such that

$$
n\left[G\left(g x_{n}, g x_{n+1}, g x_{n+1}\right)\right]^{k} \leqslant 1 \text { for all } n>n_{1},
$$

which implies

$$
\left.G\left(g x_{n}, g x_{n+1}, g x_{n+1}\right)\right] \leqslant \frac{1}{n^{\frac{1}{k}}} \text { for all } n>n_{1} .
$$

Now we prove that $\left\{g x_{n}\right\}$ is a G-Cauchy sequence. For $m>n>n_{1}$ we have

$$
G\left(g x_{n}, g x_{m}, g x_{m}\right) \leqslant \sum_{i=n}^{m-1} G\left(g x_{i}, g x_{i+1}, g x_{i+1}\right) \leqslant \sum_{i=n}^{m-1} \frac{1}{i^{\frac{1}{k}}} \leqslant \sum_{i=1}^{\infty} \frac{1}{i^{\frac{1}{k}}} .
$$

Since $0<k<1$, so $\sum_{i=1}^{\infty} \frac{1}{i \frac{1}{k}}$ converges. Therefore, $G\left(g x_{n}, g x_{m}, g x_{m}\right) \longrightarrow 0$ as $m, n \longrightarrow \infty$. Thus $\left\{g x_{n}\right\}$ is a G-Cauchy sequence in complete subspace $g(X)$, so there exists $q \in g(X)$ such that

$$
\lim _{n \rightarrow \infty} G\left(g x_{n}, g x_{n}, q\right)=\lim _{n \rightarrow \infty} G\left(g x_{n}, q, q\right)=0 .
$$

Since $q \in g(X)$, there exists $p \in X$ such that $q=g p$. Hence from (3.7), we have

$$
\lim _{n \rightarrow \infty} G\left(g x_{n}, g x_{n}, g p\right)=\lim _{n \rightarrow \infty} G\left(g x_{n}, g p, g p\right)=0 .
$$

Now we will prove that $g p \in T p$. If there exists an increasing sequence $\left\{n_{k}\right\}$ such that $g x_{n_{k}} \in T p$ for all $k \in N$, since $T p$ is closed and $g x_{n_{k}} \rightarrow g p$, we get $g p \in T p$ and the proof is complete. So we assume that there exists $n_{0} \in N$ such that $g x_{n+1} \notin T p$ for all $n \geqslant n_{0}$. Since $g x_{n+1} \in T x_{n}$, as a result, $T x_{n} \neq T p$ for all $\mathrm{n} \geqslant \mathrm{n}_{0}$ and so we have

$$
H_{G}\left(T x_{n}, T p, T p\right)>0 \text { for all } n \geqslant n_{0}
$$


Now as $g x_{n+1} \in T x_{n}$, so by Lemma 2.9, we have

$$
G\left(g x_{n+1}, T p, T p\right) \leqslant H_{G}\left(T x_{n}, T p, T p\right) .
$$

As $F$ is strictly increasing, so by (3.8), above inequality, and (3.1), we get

$$
F\left(G\left(g x_{n+1}, T p, T p\right)\right) \leqslant 2 \tau+F\left(G\left(g x_{n+1}, T p, T p\right)\right) \leqslant 2 \tau+F\left(H_{G}\left(T x_{n}, T p, T p\right)\right) \leqslant F\left(G\left(g x_{n}, g p, g p\right)\right) .
$$

Since $F$ is increasing, we have

$$
\mathrm{G}\left(\mathrm{g} \mathrm{x}_{\mathrm{n}+1}, \mathrm{Tp}, \mathrm{Tp}\right) \leqslant \mathrm{G}\left(\mathrm{g} \mathrm{x}_{\mathrm{n}}, \mathrm{gp}, \mathrm{gp}\right) .
$$

Letting $n \rightarrow \infty$ in previous inequality and using the fact that the function $\mathrm{G}$ is continuous on its three variables, we get $G(g p, T p, T p)=0$. Since $T p$ is closed we obtain that $g p \in T p$. That is $p$ is a coincidence point of $T$ and $g$. Hence $g$ and $T$ have a point of coincidence $w$. We will prove the uniqueness of a point of coincidence of $g$ and T. For this we suppose on the contrary that $w^{*}$ is another point of coincidence of $g$ and $T$ that is there exists another coincidence point $q$ of $g$ and $T$ such that $w^{*}=g q \in T q$ with $g p \neq g q$ and $T p \neq T q$. Otherwise, $p$ and $q$ will not be coincidence points. Then, $H_{G}(T q, T p, T p)>0$. Thus, we have the following assumption that

$$
G(g q, g p, g p) \leqslant H_{G}(T q, T p, T p) .
$$

Since F is increasing, so by above inequality and (3.1), we get

$$
2 \tau+F(G(g q, g p, g p)) \leqslant 2 \tau+F\left(H_{G}(T q, T p, T p)\right) \leqslant F(G(g q, g p, g p)),
$$

which further implies that

$$
F(G(g q, g p, g p)) \leqslant F(G(g q, g p, g p))-2 \tau<F(G(g q, g p, g p)) .
$$

Since F is strictly increasing, so we get

$$
\mathrm{G}(\mathrm{gq}, \mathrm{gp}, \mathrm{gp})<\mathrm{G}(\mathrm{gq}, \mathrm{gp}, \mathrm{gp}),
$$

which is a contradiction. Hence, $g p=g q$ and $T p=T q$. Hence, $g$ and $T$ have a unique point of coincidence. Suppose that $\mathrm{g}$ and $\mathrm{T}$ are weakly compatible. By applying Proposition 2.12, we get that $\mathrm{g}$ and $\mathrm{T}$ have a unique common fixed point.

Corollary 3.3. Let $(\mathrm{X}, \mathrm{G})$ be a complete $\mathrm{G}$-metric space on $\mathrm{X}$, and let $\mathrm{T}: \mathrm{X} \longrightarrow \mathrm{CB}(\mathrm{X})$. If there exist a function $\mathrm{F} \in \mathcal{F}$ and a constant $\tau>0$ such that for all $x, y, z \in X$

$$
H_{G}(T x, T y, T z)>0 \Longrightarrow 2 \tau+F\left(H_{G}(T x, T y, T z)\right) \leqslant F(G(x, y, z)),
$$

then Thas a fixed point in $\mathrm{X}$.

Proof. It follows by taking $g$ the identity on $X$ in Theorem 3.2.

Example 3.4. Let $X=[0,1]$. Define a mapping $T: X \longrightarrow C B(X)$ by $T x=\left[0, \frac{x}{25}\right]$ and define $g: X \longrightarrow X$ by $g(x)=\frac{3 x}{4}$. Define a G-metric on $X$ by $G(x, y, z)=|x-y|+|y-z|+|x-z|$. Then

(1) $g(X)$ is a G-complete subspace of $X$;

(2) $g$ and $T$ are weakly compatible;

(3) $\mathrm{T} x \subseteq g(X)$;

(4) $T$ is a $(g-F)$ contraction where $F(\alpha)=\ln (\alpha)$ and $\tau \in\left(0, \ln \left(\sqrt{\frac{75}{32}}\right)\right)$. 
Proof. The proof of (1), (2), and (3) are clear. We will prove (4). We have

$$
d_{G}(x, y)=G(x, y, y)+G(y, x, x)=4|x-y| \text { for all } x, y \in X .
$$

To prove (4), let $x, y, z \in X$. If $x=y=z=0$, then $T x=T y=T z=0$ and $H_{G}(T x, T y, T z)=0$. Thus we may assume that $x, y$ and $z$ are not all zero. Without loss of generality we assume that $x \leqslant y \leqslant z$. Then

$$
H_{G}(T x, T y, T z)=H_{G}\left(\left[0, \frac{x}{25}\right],\left[0, \frac{y}{25}\right],\left[0, \frac{z}{25}\right]\right)=\max \left\{\begin{array}{l}
\sup _{0 \leqslant a \leqslant \frac{x}{25}} G\left(a,\left[0, \frac{y}{25}\right],\left[0, \frac{z}{25}\right]\right), \\
\sup _{0 \leqslant b \leqslant \frac{y}{25}} G\left(b,\left[0, \frac{x}{25}\right],\left[0, \frac{z}{25}\right]\right), \\
\sup _{0 \leqslant c \leqslant \frac{z}{25}} G\left(c,\left[0, \frac{x}{25}\right],\left[0, \frac{y}{25}\right]\right) .
\end{array}\right\} .
$$

Since $x \leqslant y \leqslant z$, then $\left[0, \frac{x}{25}\right] \subseteq\left[0, \frac{y}{25}\right] \subseteq\left[0, \frac{z}{25}\right]$ which implies that

$$
\mathrm{d}_{\mathrm{G}}\left(\left[0, \frac{x}{25}\right],\left[0, \frac{\mathrm{y}}{25}\right]\right)=\mathrm{d}_{\mathrm{G}}\left(\left[0, \frac{\mathrm{y}}{25}\right],\left[0, \frac{z}{25}\right]\right)=\mathrm{d}_{\mathrm{G}}\left(\left[0, \frac{x}{25}\right],\left[0, \frac{z}{25}\right]\right)=0 .
$$

Now for each $0 \leqslant a \leqslant \frac{x}{25}$ we have

$$
\mathrm{G}\left(\mathrm{a},\left[0, \frac{\mathrm{y}}{25}\right],\left[0, \frac{z}{25}\right]\right)=\mathrm{d}_{\mathrm{G}}\left(\mathrm{a},\left[0, \frac{\mathrm{y}}{25}\right]\right)+\mathrm{d}_{\mathrm{G}}\left(\left[0, \frac{\mathrm{y}}{25}\right],\left[0, \frac{z}{25}\right]\right)+\mathrm{d}_{\mathrm{G}}\left(\mathrm{a},\left[0, \frac{z}{25}\right]\right)=0 .
$$

Also, for each $0 \leqslant \mathrm{~b} \leqslant \frac{y}{25}$ we have

$$
\begin{aligned}
\mathrm{G}\left(\mathrm{b},\left[0, \frac{x}{25}\right],\left[0, \frac{z}{25}\right]\right) & =\mathrm{d}_{\mathrm{G}}\left(\mathrm{b},\left[0, \frac{x}{25}\right]\right)+\mathrm{d}_{\mathrm{G}}\left(\left[0, \frac{x}{25}\right],\left[0, \frac{z}{25}\right]\right)+\mathrm{d}_{\mathrm{G}}\left(\mathrm{b},\left[0, \frac{z}{25}\right]\right) \\
& = \begin{cases}0, & \text { if } 0 \leqslant \mathrm{~b} \leqslant \frac{x}{25} \\
4 \mathrm{~b}-\frac{4 x}{25}, & \text { if } \mathrm{b} \geqslant \frac{x}{25},\end{cases}
\end{aligned}
$$

which implies that

$$
\sup _{0 \leqslant b \leqslant \frac{y}{25}} G\left(b,\left[0, \frac{x}{25}\right],\left[0, \frac{z}{25}\right]\right)=\frac{4 y-4 x}{25} .
$$

Moreover, for each $0 \leqslant c \leqslant \frac{z}{25}$ we have

$$
\begin{aligned}
\mathrm{G}\left(\mathrm{c},\left[0, \frac{x}{25}\right],\left[0, \frac{y}{25}\right]\right) & =\mathrm{d}_{\mathrm{G}}\left(\mathrm{c},\left[0, \frac{x}{25}\right]\right)+\mathrm{d}_{\mathrm{G}}\left(\left[0, \frac{x}{25}\right],\left[0, \frac{y}{25}\right]\right)+\mathrm{d}_{\mathrm{G}}\left(\mathrm{c},\left[0, \frac{\mathrm{y}}{25}\right]\right) \\
& = \begin{cases}0, & \text { if } 0 \leqslant \mathrm{c} \leqslant \frac{x}{25}, \\
4 \mathrm{c}-\frac{4 x}{25}, & \text { if } \frac{x}{25} \leqslant \mathrm{c} \leqslant \frac{y}{25}, \\
8 \mathrm{c}-\frac{4 y}{25}-\frac{4 x}{25}, & \text { if } \frac{y}{25} \leqslant \mathrm{c} \leqslant \frac{z}{25},\end{cases}
\end{aligned}
$$

which implies that

$$
\sup _{0 \leqslant c \leqslant \frac{z}{25}} G\left(c,\left[0, \frac{x}{25}\right],\left[0, \frac{y}{25}\right]\right)=\frac{8 z-4 y-4 x}{25}
$$

Thus we deduce that

$$
\begin{aligned}
\mathrm{H}_{\mathrm{G}}(\mathrm{T} x, \mathrm{Ty}, \mathrm{Tz}) & =\max \left\{0, \frac{4 y-4 x}{25}, \frac{8 z-4 y-4 x}{25}\right\} \\
& =\frac{8 z-4 y-4 x}{25} \\
& \leqslant \frac{8 z-8 x}{25} \\
& =\frac{8}{25}|z-x|
\end{aligned}
$$




$$
\begin{aligned}
& =\frac{32}{75}\left|\frac{3 z}{4}-\frac{3 x}{4}\right| \\
& =\frac{32}{75}|g z-g x| \\
& \leqslant \frac{32}{75}(|g x-g y|+|g y-g z|+|g x-g z|) \\
& =\frac{32}{75} G(g x, g y, g z) .
\end{aligned}
$$

Therefore,

$$
\frac{75}{32} H_{G}(T x, T y, T z) \leqslant G(g x, g y, g z)
$$

By using $F(\alpha)=\ln (\alpha)$ we get

$$
\ln \left(\frac{75}{32}\right)+\ln \left(H_{G}(T x, T y, T z)\right) \leqslant \ln (G(g x, g y, g z)) .
$$

Thus, for all $x, y, z \in X$ with $H_{G}(T x, T y, T z)>0$ we have

$$
2 \tau+F\left(H_{G}(T x, T y, T z)\right) \leqslant F(G(g x, g y, g z)), \text { where } 0<\tau<\ln \left(\sqrt{\frac{75}{32}}\right) .
$$

Hence, $T$ is a $(g-F)$ contraction. On the other hand it is clear that $x=0$ is the only coincidence point and all other hypotheses of Theorem 3.2 are satisfied. So the mappings $T$ and $g$ have a unique common fixed point which is $u=0$.

\section{Generalized Mizoguchi-Takahashi's contractions}

In 2012, Tahat et al. [34] utilized the concept of G-metric spaces and obtained point of coincidence and common fixed points of a hybrid pair of single-valued and multi-valued mappings. They proved the following fixed point theorem as a main result.

Theorem 4.1 ([34]). Let $(\mathrm{X}, \mathrm{G})$ be a $\mathrm{G}$-metric space and let $\mathrm{T}: \mathrm{X} \longrightarrow \mathrm{CB}(\mathrm{X})$ be a multi-valued mapping and $\mathrm{g}: \mathrm{X} \rightarrow \mathrm{X}$ a self-mapping. Assume that there exists a function $\alpha:[0,+\infty) \rightarrow[0,1)$ satisfying

$$
\lim _{r \rightarrow t^{+}} \sup \alpha(r)<1
$$

for every $t \geqslant 0$ such that

$$
\mathrm{H}_{\mathrm{G}}(T x, T y, T z) \leqslant \alpha(G(g x, g y, g z)) G(g x, g y, g z)
$$

for all $x, y, z \in X$. If for any $x \in X, T x \subseteq g(X)$ and $g(X)$ is a $\mathrm{G}$-complete subspace of $\mathrm{X}$, then $\mathrm{g}$ and $\mathrm{T}$ have $a$ point of coincidence in $X$. Furthermore, if we assume that $\mathrm{gp} \in \mathrm{Tp}$ and $\mathrm{gq} \in \mathrm{Tq}$ implies $\mathrm{G}(\mathrm{gq}, \mathrm{gp}, \mathrm{gp}) \leqslant \mathrm{H}_{\mathrm{G}}(\mathrm{Tq}, \mathrm{Tp}, \mathrm{Tp})$, then

(i) g and T have a unique point of coincidence;

(ii) in addition, if $\mathrm{g}$ and $\mathrm{T}$ are weakly compatible, then $\mathrm{g}$ and $\mathrm{T}$ have a unique common fixed point.

Recently, Javahernia et al. [18] generalized the above function by introducing the notion of generalized Mizoguchi-Takahashi function in such a way.

Definition 4.2 ([18]). A function $\alpha: R \times R \rightarrow R$ is called a generalized Mizoguchi-Takahashi function (shortly, generalized MT-function) if the following conditions hold:

(a1) $0<\alpha(u, v)<1$ for all $u, v>0$; 
(a2) for any bounded sequence $\left(u_{n}\right) \subset(0,+\infty)$ and any non-increasing sequence $\left(v_{n}\right) \subset(0,+\infty)$, we have

$$
\lim _{n \rightarrow \infty} \sup \alpha\left(u_{n}, v_{n}\right)<1 \text {. }
$$

Consistent with Javahernia et al. [18], we denote by $\Lambda$ the set of all functions $\alpha: R \times R \rightarrow R$ satisfying the conditions (a1)-(a2).

The basic aim of this section is to generalize the results of Tahat et al. [34] by utilizing the notion of generalized Mizoguchi-Takahashi function. Now we give the main result of this section.

Theorem 4.3. Let $(\mathrm{X}, \mathrm{G})$ be a $\mathrm{G}$-metric space. Let $\mathrm{T}: \mathrm{X} \longrightarrow \mathrm{CB}(\mathrm{X})$ be a multi-valued mapping and $\mathrm{g}: \mathrm{X} \rightarrow \mathrm{X}$ a self-mapping. If for any $\mathrm{x} \in \mathrm{X}, \mathrm{T} x \subseteq \mathrm{g}(\mathrm{X}), \mathrm{g}(\mathrm{X})$ is a $\mathrm{G}$-complete subspace of $\mathrm{X}$, and there exists $\alpha \in \Lambda$ such that

$$
H_{G}(T x, T y, T z) \leqslant \alpha\left(H_{G}(T x, T y, T z), G(g x, g y, g z)\right) G(g x, g y, g z)
$$

for all $x, y, z \in X$, then $g$ and $\mathrm{T}$ have a point of coincidence in X. Furthermore, if we assume that

$$
g x^{*} \in \mathrm{T} x^{*} \text { and } \mathrm{g} \hat{x} \in \mathrm{T} \hat{x} \text { implies } \mathrm{G}\left(\mathrm{g} \hat{x}, g x^{*}, g x^{*}\right) \leqslant \mathrm{H}_{\mathrm{G}}\left(\mathrm{T} \hat{x}, T x^{*}, T x^{*}\right),
$$

then

(i) g and Thave a unique point of coincidence;

(ii) in addition, if $\mathrm{g}$ and $\mathrm{T}$ are weakly compatible, then $\mathrm{g}$ and $\mathrm{T}$ have a unique common fixed point.

Proof. Let $x_{0}$ be an arbitrary point of $X$. Then by the given assumptions, there exists a point $x_{1}$ in $X$ such that $g x_{1} \in T x_{0}$. If $g x_{1}=g x_{0}$, then we have nothing to prove and $x_{0}$ is the required point. Thus we assume that $g x_{0} \neq g x_{1}$, and so $G\left(g x_{0}, g x_{1}, g x_{1}\right)>0$. Now if $T x_{0}=T x_{1}$, then $g x_{1} \in T x_{1}$ and so $x_{1}$ is the required point and nothing to do. Thus we assume that $g x_{0} \neq g x_{1}$ and $T x_{0} \neq T x_{1}$ and so $G\left(g x_{0}, g x_{1}, g x_{1}\right)>0$ and $\mathrm{H}_{\mathrm{G}}\left(T x_{0}, T x_{1}, T x_{1}\right)>0$. From the inequality (4.1), we have

$$
H_{G}\left(T x_{0}, T x_{1}, T x_{1}\right) \leqslant \alpha\left(H_{G}\left(T x_{0}, T x_{1}, T x_{1}\right), G\left(g x_{0}, g x_{1}, g x_{1}\right)\right) G\left(g x_{0}, g x_{1}, g x_{1}\right) .
$$

Taking

$$
\epsilon_{1}=\left(\frac{1}{\sqrt{\alpha\left(\mathrm{H}_{\mathrm{G}}\left(T x_{0}, T x_{1}, T x_{1}\right), \mathrm{G}\left(g x_{0}, g x_{1}, g x_{1}\right)\right)}}-1\right) H_{G}\left(T x_{0}, T x_{1}, T x_{1}\right),
$$

then by Lemma 2.10 and (4.2), we have

$$
\mathrm{G}\left(g x_{1}, g x_{2}, g x_{2}\right) \leqslant H_{G}\left(T x_{0}, T x_{1}, T x_{1}\right)+\epsilon_{1}=\frac{H_{G}\left(T x_{0}, T x_{1}, T x_{1}\right)}{\sqrt{\alpha\left(H_{G}\left(T x_{0}, T x_{1}, T x_{1}\right), G\left(g x_{0}, g x_{1}, g x_{1}\right)\right)}} .
$$

Since $T x_{1} \subseteq g(X)$, so there exists a point $x_{2}$ in $X$ such that $g x_{2} \in T x_{1}$. If $g x_{1}=g x_{2}$, then $x_{1}$ is the required point. So we assume that $g x_{1} \neq g x_{2}$, and $T x_{1} \neq T x_{2}$, so $G\left(g x_{1}, g x_{2}, g x_{2}\right)>0$ and $H_{G}\left(T x_{1}, T x_{2}, T x_{2}\right)=0$.

From the inequality (4.1), we have

$$
H_{G}\left(T x_{1}, T x_{2}, T x_{2}\right) \leqslant \alpha\left(H_{G}\left(T x_{1}, T x_{2}, T x_{2}\right), G\left(g x_{1}, g x_{2}, g x_{2}\right)\right) G\left(g x_{1}, g x_{2}, g x_{2}\right) .
$$

Taking

$$
\epsilon_{2}=\left(\frac{1}{\sqrt{\alpha\left(\mathrm{H}_{\mathrm{G}}\left(\mathrm{T} x_{1}, T x_{2}, T x_{2}\right), \mathrm{G}\left(g x_{1}, g x_{2}, g x_{2}\right)\right)}}-1\right) \mathrm{H}_{\mathrm{G}}\left(T x_{1}, T x_{2}, T x_{2}\right),
$$

then by Lemma 2.10 and (4.3), we get

$$
\mathrm{G}\left(g x_{2}, g x_{3}, g x_{3}\right) \leqslant H_{G}\left(T x_{1}, T x_{2}, T x_{2}\right)+\epsilon_{2}=\frac{H_{G}\left(T x_{1}, T x_{2}, T x_{2}\right)}{\sqrt{\alpha\left(H_{G}\left(T x_{1}, T x_{2}, T x_{2}\right), G\left(g x_{1}, g x_{2}, g x_{2}\right)\right)}} .
$$


By repeating the above process, we can construct a sequence $\left\{g x_{k}\right\}$ such that $g x_{k+1} \in T x_{k}$, where

$$
\mathrm{G}\left(g x_{k-1}, g x_{k}, g x_{k}\right)>0 \text { and } H_{G}\left(T x_{k-1}, T x_{k}, T x_{k}\right)>0 .
$$

Also

$$
H_{G}\left(T x_{k-1}, T x_{k}, T x_{k}\right) \leqslant \alpha\left(H_{G}\left(T x_{k-1}, T x_{k}, T x_{k}\right), G\left(g x_{k-1}, g x_{k}, g x_{k}\right)\right) G\left(g x_{k-1}, g x_{k}, g x_{k}\right) .
$$

Thus,

$$
\begin{aligned}
G\left(g x_{k}, g x_{k+1}, g x_{k+1}\right) & \leqslant H_{G}\left(T x_{k-1}, T x_{k}, T x_{k}\right)+\epsilon_{k} \\
& =\frac{H_{G}\left(T x_{k-1}, T x_{k}, T x_{k}\right)}{\sqrt{\alpha\left(H_{G}\left(T x_{k-1}, T x_{k}, T x_{k}\right), G\left(g x_{k-1}, g x_{k}, g x_{k}\right)\right)}} .
\end{aligned}
$$

From the inequalities (4.4) and (4.5), we have

$$
G\left(g x_{k}, g x_{k+1}, g x_{k+1}\right) \leqslant \sqrt{\alpha\left(H_{G}\left(T x_{k-1}, T x_{k}, T x_{k}\right), G\left(g x_{k-1}, g x_{k}, g x_{k}\right)\right)} G\left(g x_{k-1}, g x_{k}, g x_{k}\right),
$$

which shows that the sequence of nonnegative numbers $\left\{d_{k}\right\}$ given by

$$
d_{k}=G\left(g x_{k-1}, g x_{k}, g x_{k}\right)
$$

for $k=1,2, \cdots$, is non-increasing, where $d_{k} \geqslant 0$. Hence, there exists a nonnegative number $d$ such that

$$
\mathrm{d}=\lim _{\mathrm{k} \rightarrow \infty} \mathrm{d}_{\mathrm{k}}=\inf _{\mathrm{k} \in \mathrm{N}} \mathrm{d}_{\mathrm{k}} \geqslant 0 .
$$

As, $H_{G}\left(T x_{k-1}, T x_{k}, T x_{k}\right)>0$ and $G\left(g x_{k-1}, g x_{k}, g x_{k}\right)>0$, so from (4.4) we have

$$
H_{G}\left(T x_{k-1}, T x_{k}, T x_{k}\right) \leqslant G\left(g x_{k-1}, g x_{k}, g x_{k}\right),
$$

which shows that $\left\{\mathrm{H}_{\mathrm{G}}\left(T x_{k-1}, T x_{k}, T x_{k}\right)\right\}$ is a bounded sequence. By (a2) we have

$$
\lim _{n \rightarrow \infty} \sup \alpha\left(H_{G}\left(T x_{k-1}, T x_{k}, T x_{k}\right), G\left(g x_{k-1}, g x_{k}, g x_{k}\right)\right)<1 .
$$

Now we claim that $d=0$. Suppose $d>0$, then by (4.7), (4.8), and taking the limsup on both sides of (4.6) we get

$$
d \leqslant \sqrt{\lim _{k \rightarrow \infty} \sup \alpha\left(H_{G}\left(T x_{k-1}, T x_{k}, T x_{k}\right), G\left(g x_{k-1}, g x_{k}, g x_{k}\right)\right)} d<d .
$$

So, this contradiction implies that

$$
\lim _{k \rightarrow \infty} d_{k}=\inf _{k \in N} d_{k}=0
$$

Therefore,

$$
\lim _{k \rightarrow \infty} G\left(g x_{k}, g x_{k+1}, g x_{k+1}\right)=\inf _{k \in N} G\left(g x_{k}, g x_{k+1}, g x_{k+1}\right)=0 .
$$

Now we prove that $\left\{g x_{k}\right\}$ is a Cauchy sequence in $X$. For each $k \in \mathbb{N}$, let

$$
q_{k}=\sqrt{\alpha\left(H_{G}\left(T x_{k-1}, T x_{k}, T x_{k}\right), G\left(g x_{k-1}, g x_{k}, g x_{k}\right)\right)} .
$$

Then, $\mathrm{q}_{k} \in(0,1)$ for all $k \in \mathbb{N}$. By $(4.6)$, we have

$$
G\left(g x_{k}, g x_{k+1}, g x_{k+1}\right) \leqslant q_{k} G\left(g x_{k-1}, g x_{k}, g x_{k}\right)
$$

for all $k \in \mathbb{N}$. From (4.8), we have $\lim _{k \rightarrow \infty} \sup q_{k}<1$, so there exist $c \in[0,1)$ and $k_{0} \in \mathbb{N}$ such that $q_{k}<c$ for all $k \in \mathbb{N}$ with $k \geqslant k_{0}$. Since $q_{k} \in(0,1)$ for all $k \in \mathbb{N}$ and $c \in[0,1)$. Thus from (4.9) for $k \geqslant k_{0}$, we conclude that

$$
G\left(g x_{k}, g x_{k+1}, g x_{k+1}\right) \leqslant q_{k} G\left(g x_{k-1}, g x_{k}, g x_{k}\right)
$$




$$
\begin{aligned}
& \leqslant q_{k} q_{k-1} G\left(g x_{k-2}, g x_{k-1}, g x_{k-1}\right) \\
& \vdots \\
& \leqslant q_{k} q_{k-1} \cdots q_{k_{0}} G\left(g x_{0}, g x_{1}, g x_{1}\right) \\
& \leqslant c^{k-k_{0}+1} G\left(g x_{0}, g x_{1}, g x_{1}\right)
\end{aligned}
$$

Let $\lambda_{k}=\frac{\mathrm{c}^{\mathrm{k}-\mathrm{k}_{0}+1}}{1-\mathrm{c}} \mathrm{G}\left(\mathrm{gx_{0 }}, \mathrm{gx_{1 }}, \mathrm{gx_{1 }}\right), \mathrm{k} \in \mathbb{N}$. For $\mathrm{k} \in \mathbb{N}$ with $\mathrm{k} \geqslant \mathrm{k}_{0}$ and $\mathrm{m}$ is a positive arbitrary number, then from the last inequality and (G5), we have

$$
G\left(g x_{k}, g x_{k+m}, g x_{k+m}\right) \leqslant \sum_{i=k}^{k+m-1} G\left(g x_{i}, g x_{i+1}, g x_{i+1}\right) \leqslant \lambda_{k} .
$$

Since $c \in[0,1)$, as a result, $\lim _{k \rightarrow \infty} \lambda_{k}=0$. Hence $\lim _{k \rightarrow \infty} G\left(g x_{k}, g x_{k+m}, g x_{k+m}\right)=0$. Thus the sequence $\left\{g x_{k}\right\}$ is G-Cauchy in the complete subspace $g(X)$. Thus there exists $x^{\prime} \in g(X)$ such that from Proposition 2.3, we have

$$
\lim _{k \rightarrow \infty} G\left(g x_{k}, g x_{k}, x^{\prime}\right)=\lim _{k \rightarrow \infty} G\left(g x_{k}, x^{\prime}, x^{\prime}\right)=0 .
$$

Since $x^{\prime} \in g(X)$, so there exists $x^{*} \in X$ such that $x^{\prime}=g x^{*}$. Thus from (4.10), we have

$$
\lim _{k \rightarrow \infty} G\left(g x_{k}, g x_{k}, g x^{*}\right)=\lim _{k \rightarrow \infty} G\left(g x_{k}, g x^{*}, g x^{*}\right)=0 .
$$

We claim that $g x^{*} \in \mathrm{T} x^{*}$. From (4.1) and (4.11), we have

$$
\begin{aligned}
\lim _{k \rightarrow \infty} G\left(g x_{k+1}, T x^{*}, T x^{*}\right) & \leqslant \lim _{k \rightarrow \infty} H_{G}\left(T x_{k}, T x^{*}, T x^{*}\right) \\
& \leqslant \lim _{k \rightarrow \infty} \alpha\left(H_{G}\left(T x_{k-1}, T x^{*}, T x^{*}\right), G\left(g x_{k}, g x^{*}, g x^{*}\right)\right) G\left(g x_{k}, g x^{*}, g x^{*}\right) \\
& =0 .
\end{aligned}
$$

Hence, $\mathrm{G}\left(g x^{*}, T x^{*}, T x^{*}\right)=0$, that is $g x^{*} \in T x^{*}$. Thus $T$ and $g$ have a point of coincidence, i.e., $x^{*}$. Now we prove that this point of coincidence is unique. We suppose on the contrary that there exists another $\hat{x}$ such that $g \hat{x} \in \mathrm{T} \hat{x}$ but $g \hat{x} \neq g x^{*}$. By (4.1) and this assumption, we have

$$
\mathrm{G}\left(g \hat{x}, g x^{*}, g x^{*}\right) \leqslant H_{G}\left(T \hat{x}, T x^{*}, T x^{*}\right) \leqslant \alpha\left(H_{G}\left(T \hat{x}, T x^{*}, T x^{*}\right), G\left(g \hat{x}, g x^{*}, g x^{*}\right)\right) G\left(g \hat{x}, g x^{*}, g x^{*}\right)
$$

as $\mathrm{H}_{\mathrm{G}}\left(\mathrm{T} \hat{x}, T x^{*}, T x^{*}\right)>0$ and $\mathrm{G}\left(\mathrm{g} \hat{x}, g x^{*}, g x^{*}\right)>0$, so

$$
\alpha\left(H_{G}\left(T \hat{x}, T x^{*}, T x^{*}\right), G\left(g \hat{x}, g x^{*}, g x^{*}\right)\right)<1 .
$$

Thus we get

$$
\mathrm{G}\left(\mathrm{g} \hat{x}, g x^{*}, g x^{*}\right)<\mathrm{G}\left(\mathrm{g} \hat{x}, g x^{*}, g x^{*}\right),
$$

which contradicts to the fact that $g \hat{x} \neq g x^{*}$. Thus $g \hat{x}=g x^{*}$. In view of

$$
H_{G}\left(T \hat{x}, T x^{*}, T x^{*}\right) \leqslant \alpha\left(H_{G}\left(T \hat{x}, T x^{*}, T x^{*}\right), G\left(g \hat{x}, g x^{*}, g x^{*}\right)\right) G\left(g \hat{x}, g x^{*}, g x^{*}\right)=0,
$$

which implies that $T \hat{x}=T x^{*}$. Thus, $T$ and $g$ have a unique point of coincidence. Suppose that $g$ and $T$ are weakly compatible. By applying Proposition 2.12, we obtain that $\mathrm{g}$ and $\mathrm{T}$ have a unique common fixed point.

Corollary 4.4. Theorem 4.1 follows from Theorem 4.3 by taking $\alpha(u, v)=\varphi(v)$.

Corollary 4.5. Corollary 2.2 of [34] can be obtained by taking $\alpha(u, v)=\mu$ in above corollary. 
Theorem 4.6. Let $(\mathrm{X}, \mathrm{G})$ be a $\mathrm{G}$-metric space. Let $\mathrm{T}: \mathrm{X} \longrightarrow \mathrm{CB}(\mathrm{X})$ be a multi-valued mapping and $\mathrm{g}: \mathrm{X} \rightarrow \mathrm{X}$ be a self-mapping. If for any $\mathrm{x} \in \mathrm{X}, \mathrm{T} \mathrm{X} \subseteq \mathrm{g}(\mathrm{X})$ and $\mathrm{g}(\mathrm{X})$ is a $\mathrm{G}$-complete subspace of $\mathrm{X}$ such that

$$
\mathrm{H}_{\mathrm{G}}(T x, T y, T z) \leqslant \varphi(\mathrm{G}(\mathrm{gx}, \mathrm{gy}, \mathrm{gz}))
$$

for all $x, y, z \in X$, where $\varphi:[0, \infty) \rightarrow[0,1)$ is a function such that $\varphi(v)<v$ and $\lim \sup _{v \rightarrow \mathfrak{u}^{+}} \frac{\varphi(v)}{v}<1$, then $\mathrm{g}$ and $\mathrm{T}$ have a point of coincidence in $\mathrm{X}$. Furthermore, if we assume that $\mathrm{g} x^{*} \in \mathrm{T} x^{*}$ and $\mathrm{g} \hat{\mathrm{x}} \in \mathrm{T} \hat{\mathrm{x}}$ implies $\mathrm{G}\left(\mathrm{g} \hat{\mathrm{x}}, \mathrm{g} \mathrm{x}^{*}, \mathrm{gx^{* }}\right) \leqslant \mathrm{H}_{\mathrm{G}}\left(\mathrm{T} \hat{\mathrm{x}}, \mathrm{T} x^{*}, \mathrm{~T} x^{*}\right)$, then

(i) $\mathrm{g}$ and $\mathrm{T}$ have a unique point of coincidence;

(ii) in addition, if $\mathrm{g}$ and $\mathrm{T}$ are weakly compatible, then $\mathrm{g}$ and $\mathrm{T}$ have a unique common fixed point.

Proof. Take $\alpha(u, v)=\frac{\varphi(v)}{v}$ in Theorem 4.3.

Javahernia et al. [18] also introduced the concept of weak l.s.c. in the following way.

Definition 4.7. A function $\phi:[0, \infty) \rightarrow[0, \infty)$ is said to be weak l.s.c. function if for each bounded sequence $\left\{u_{n}\right\} \subset(0,+\infty)$, we have

$$
\lim _{n \rightarrow \infty} \inf \phi\left(u_{n}\right)>0 .
$$

Consistent with Javahernia et al. [18], we denote by $\digamma$, the set of all functions $\phi:[0, \infty) \rightarrow[0, \infty)$ satisfying the above condition.

Theorem 4.8. Let $(\mathrm{X}, \mathrm{G})$ be a $\mathrm{G}$-metric space. Let $\mathrm{T}: \mathrm{X} \longrightarrow \mathrm{CB}(\mathrm{X})$ be a multi-valued mapping and $\mathrm{g}: \mathrm{X} \rightarrow \mathrm{X}$ be a self-mapping. If for any $\mathrm{x} \in \mathrm{X}, \mathrm{T} \mathrm{X} \subseteq \mathrm{g}(\mathrm{X})$ and $\mathrm{g}(\mathrm{X})$ is a $\mathrm{G}$-complete subspace of $\mathrm{X}$ such that

$$
H_{G}(T x, T y, T z) \leqslant G(g x, g y, g z)-\phi(G(g x, g y, g z))
$$

for all $x, y, z \in X$, where $\phi:[0, \infty) \rightarrow[0, \infty)$ is such that $\phi(0)=0, \phi(v)<v$ and $\phi \in \digamma$, then $\mathrm{g}$ and $\mathrm{T}$ have a point of coincidence in $\mathrm{X}$. Furthermore, if we assume that $\mathrm{gx}^{*} \in \mathrm{T} x^{*}$ and $\mathrm{g} \hat{\mathrm{x}} \in \mathrm{T} \hat{\mathrm{x}}$ implies $\mathrm{G}\left(\mathrm{g} \hat{\mathrm{x}}, \mathrm{gx} \mathrm{x}^{*}, \mathrm{gx^{* }}\right) \leqslant$ $\mathrm{H}_{\mathrm{G}}\left(\mathrm{T} \hat{x}, \mathrm{Tx}^{*}, \mathrm{~T} x^{*}\right)$, then

(i) $\mathrm{g}$ and $\mathrm{T}$ have a unique point of coincidence;

(ii) in addition, if $\mathrm{g}$ and $\mathrm{T}$ are weakly compatible, then $\mathrm{g}$ and $\mathrm{T}$ have a unique common fixed point.

Proof. Define $\alpha(u, v)=1-\frac{\phi(u)}{u}$ for all $u, v>0$. Since for each bounded sequence $\left\{u_{n}\right\} \subset(0,+\infty)$, we have $\lim _{n \rightarrow \infty} \inf \phi\left(u_{n}\right)>0$, so $\lim _{n \rightarrow \infty} \inf \frac{\phi\left(u_{n}\right)}{u_{n}}>0$. Thus

$$
\lim _{n \rightarrow \infty} \sup \left(1-\frac{\phi\left(u_{n}\right)}{u_{n}}\right)=1-\lim _{n \rightarrow \infty} \inf \frac{\phi\left(u_{n}\right)}{u_{n}}<0 .
$$

This shows that $\alpha \in \Lambda$. Also

$$
H_{G}(T x, T y, T z) \leqslant \alpha\left(H_{G}(T x, T y, T z), G(g x, g y, g z)\right) G(g x, g y, g z) .
$$

Thus by Theorem 4.1, we get $g$ and $T$ have a unique common fixed point.

\section{Application}

In this section, we will use Corollary 3.3 to show that there is a solution to the following integral equation:

$$
u(t)=\int_{a}^{b} H(t, s) K(s, u(s)) d s, \quad t \in[a, b] .
$$

Let $X=(C[a, b], R)$ denote the set of all continuous functions from $[a, b]$ to $\mathbf{R}$. Define a mapping $T: X \rightarrow X$ by

$$
\mathrm{Tu}(\mathrm{t})=\int_{a}^{b} H(t, s) K(s, u(s)) d s, \quad t \in[a, b]
$$


Theorem 5.1. Consider equation (5.1) and suppose:

1. $H:[a, b] \times[a, b] \rightarrow[0, \infty)$ is a continuous function;

2. $\mathrm{K}:[\mathrm{a}, \mathrm{b}] \times \mathbf{R} \rightarrow \mathbf{R}$, where $\mathrm{K}$ is continuous mapping;

3. $\max _{\mathrm{t} \in[\mathrm{a}, \mathrm{b}]} \int_{\mathrm{a}}^{\mathrm{b}} \mathrm{H}(\mathrm{t}, \mathrm{s}) \mathrm{ds}<\mathrm{e}^{-2 \tau}$ for some $\tau \in(0, \infty)$;

4. For all $\mathrm{u}(\mathrm{s}), v(\mathrm{~s}) \in \mathrm{X}, \mathrm{s} \in[\mathrm{a}, \mathrm{b}]$, we have

$$
|\mathrm{K}(\mathrm{s}, \mathrm{u}(\mathrm{s}))-\mathrm{K}(\mathrm{s}, v(\mathrm{~s}))| \leqslant|\mathrm{u}(\mathrm{s})-v(\mathrm{~s})| .
$$

Then, equation (5.1) has a solution.

Proof. Let $\mathrm{X}$ and $\mathrm{T}$ be as defined above. For all $u, v, w \in X$ define the G-metric on $\mathrm{X}$ by

$$
\mathrm{G}(u, v, w)=d(u, v)+d(v, w)+d(u, w),
$$

where

$$
d(u, v)=\sup _{t \in[a, b]}|u(t)-v(t)| \text {. }
$$

Clearly, $(X, G)$ is a complete $G$-metric space, since $(X, d)$ is complete metric space. Now, Let $u(t), v(t) \in X$, then from definition 5.2, (3) and (4) we have

$$
\begin{aligned}
|\mathrm{Tu}(\mathrm{t})-\mathrm{T} v(t)| & =\left|\int_{a}^{b} H(t, s)[K(s, u(s))-K(s, v(s))] d s\right| \\
& \leqslant \int_{a}^{b} H(t, s) \mid K(s, u(s))-K(s, v(s) \mid d s \\
& \leqslant \int_{a}^{b} H(t, s)|u(s)-v(s)| d s \\
& \leqslant \int_{a}^{b} H(t, s) \sup _{s \in[a, b]}|u(s)-v(s)| d s \\
& =\sup _{t \in[a, b]}|u(t)-v(t)| \int_{a}^{b} H(t, s) d s \\
& \leqslant e^{-2 \tau} \sup _{t \in[a, b]}|u(t)-v(t)| .
\end{aligned}
$$

Hence,

$$
\sup _{t \in[a, b]}|T u(t)-T v(t)| \leqslant e^{-2 \tau} \sup _{t \in[a, b]}|u(t)-v(t)| .
$$

Similarly, we have

$$
\sup _{t \in[a, b]}|T v(t)-T w(t)| \leqslant e^{-2 \tau} \sup _{t \in[a, b]}|v(t)-w(t)|
$$

and

$$
\sup _{t \in[a, b]}|T u(t)-T w(t)| \leqslant e^{-2 \tau} \sup _{t \in[a, b]}|u(t)-w(t)| .
$$

Therefore, from (5.3), (5.4), and (5.5) we have

$$
\begin{aligned}
& \sup _{t \in[a, b]}|T u(t)-T v(t)|+\sup _{t \in[a, b]}|T v(t)-T w(t)|+\sup _{t \in[a, b]}|T u(t)-T w(t)| \\
& \quad \leqslant e^{-2 \tau}\left[\sup _{t \in[a, b]}|u(t)-v(t)|+\sup _{t \in[a, b]}|v(t)-w(t)|+\sup _{t \in[a, b]}|u(t)-w(t)|\right],
\end{aligned}
$$


which implies

$$
G(T u, T v, T w) \leqslant e^{-2 \tau} G(u, v, w)
$$

Thus,

$$
\ln (\mathrm{G}(\mathrm{Tu}, \mathrm{T} v, \mathrm{Tw})) \leqslant-2 \tau+\ln (\mathrm{G}(\mathrm{u}, v, w))
$$

and so

$$
2 \tau+\ln (\mathrm{G}(\mathrm{Tu}, \mathrm{T} v, \mathrm{~T} w)) \leqslant \ln (\mathrm{G}(\mathrm{u}, v, w)) .
$$

Now, we observe that $2 \tau+F(G(T u, T v, T w)) \leqslant F(G(u, v, w))$ is satisfied for $F(\alpha)=\ln (\alpha)$ for all $\alpha \in X$. Therefore, all conditions of Corollary 3.3 are satisfied. As a result of Corollary 3.3, the mapping $T$ has fixed point in $\mathrm{X}$ which is a solution of (5.1).

The following example illustrates the validity of Theorem 5.1.

Example 5.2. The following integral equation has a solution in $X=(C[\ln (2), \ln (3)], \mathbf{R})$.

$$
u(t)=\int_{\ln (2)}^{\ln (3)} \cosh (s t) u(s) d s, \quad t \in[\ln (2), \ln (3)] .
$$

Proof. Let $\mathrm{T}: \mathrm{X} \rightarrow \mathrm{X}$ be defined as $\mathrm{Tu}(\mathrm{t})=\int_{\ln (2)}^{\ln (3)} \cosh (\mathrm{st}) \mathrm{u}(\mathrm{s}) \mathrm{ds}, \mathrm{t} \in[\ln (2), \ln (3)]$. By specifying $\mathrm{H}(\mathrm{t}, \mathrm{s})=$ $\cosh (s t), K(s, t)=t$, and $\tau \geqslant \frac{18}{100}$ in Theorem 5.1, we get that:

1. the function $\mathrm{H}(\mathrm{t}, \mathrm{s})$ is continuous on $[\ln (2), \ln (3)] \times[\ln (2), \ln (3)]$;

2. $K(s, t)$ is continuous on $[\ln (2), \ln (3)] \times \mathbf{R}$ for all $s \in[\ln (2), \ln (3)]$;

3.

$$
\begin{aligned}
\max _{\mathrm{t} \in[\ln (2), \ln (3)]} \int_{\ln (2)}^{\ln (3)} \cosh (s \mathrm{t}) \mathrm{ds} & =\max _{\mathrm{t} \in[\ln (2), \ln (3)]} \frac{\sinh \left(\ln \left(3^{\mathrm{t}}\right)\right)-\sinh \left(\ln \left(2^{\mathrm{t}}\right)\right)}{\mathrm{t}} \\
& =\max _{\mathrm{t} \in[\ln (2), \ln (3)]} \frac{3^{\mathrm{t}}-3^{-\mathrm{t}}-2^{\mathrm{t}}+2^{-\mathrm{t}}}{2 \mathrm{t}} \\
& <0.7 \leqslant \mathrm{e}^{-2 \tau} ;
\end{aligned}
$$

4. for all $u(s), v(s) \in X$ it is clear that condition 4 in Theorem 5.1 is satisfied.

Therefore, all conditions of Theorem 5.1 are satisfied, hence the mapping $T$ has a fixed point in $X$, which is a solution to equation (5.6).

\section{Acknowledgment}

The authors are grateful to the referees of this paper who helped us to improve this paper in several places.

\section{References}

[1] M. Abbas, B. Ali, S. Romaguera, Fixed and periodic points of generalized contractions in metric spaces, Fixed Point Theory Appl., 2013 (2013), 11 pages. 1

[2] M. Abbas, T. Nazir, W. Shatanawi, Z. Mustafa, Fixed and related fixed point theorems for three maps in G-metric spaces, Hacet. J. Math. Stat., 41 (2012), 291-306. 1

[3] M. Abbas, B. E. Rhoades, Fixed and periodic point results in cone metric spaces, Appl. Math. Lett., 22 (2009), 511-515. 1

[4] Ö. Acar, I. Altun, A fixed point theorem for multivalued mappings with $\delta$-distance, Abstr. Appl. Anal., 2014 (2014), 5 pages. 1

[5] M. Arshad, S. U. Khan, J. Ahmad, Fixed point results for f-contractions involving some new rational expressions, JP J. Fixed Point Theory Appl., 11 (2016), 79-97. 
[6] S. Banach, Sur les opérations dans les ensembles abstraits et leur application aux équations intégrales, Fund. Math., 3 (1922), 133-181. 1

[7] A. Branciari, A fixed point theorem of Banach-Caccioppoli type on a class of generalized metric spaces, Publ. Math. Debrecen, 57 (2000), 31-37. 1

[8] L. B. Ćirić, A generalization of Banach's contraction principle, Proc. Amer. Math. Soc., 45 (1974), 267-273. 1

[9] B. C. Dhage, Generalised metric spaces and mappings with fixed point, Bull. Calcutta Math. Soc., 84 (1992), 329-336. 1

[10] M. Edelstein, On fixed and periodic points under contractive mappings, J. London Math. Soc., 37 (1962), $74-79$.

[11] B. Fisher, Set-valued mappings on metric spaces, Fund. Math., 112 (1981), 141-145.

[12] M. A. Geraghty, On contractive mappings, Proc. Amer. Math. Soc., 40 (1973), 604-608.

[13] L.-G. Huang, X. Zhang, Cone metric spaces and fixed point theorems of contractive mappings, J. Math. Anal. Appl., 332 (2007), 1468-1476. 1

[14] N. Hussain, J. Ahmad, L. Ćirić, A. Azam, Coincidence point theorems for generalized contractions with application to integral equations, Fixed Point Theory Appl., 2015 (2015), 13 pages.

[15] A. Hussain, M. Arshad, S. U. Khan, $\tau$-Generalization of fixed point results for F-contraction, Bangmod Int. J. Math. Comp. Sci., 1 (2015), 127-137.

[16] N. Hussain, E. Karapınar, P. Salimi, F. Akbar, $\alpha$-admissible mappings and related fixed point theorems, J. Inequal. Appl., 2013 (2013), 11 pages.

[17] N. Hussain, P. Salimi, Suzuki-Wardowski type fixed point theorems for $\alpha$-GF-contractions, Taiwanese J. Math., 18 (2014), 1879-1895.

[18] M. Javahernia, A. Razani, F. Khojasteh, Common fixed point of the generalized Mizoguchi-Takahashi's type contractions, Fixed Point Theory Appl., 2014 (2014), 12 pages. 4, 4.2, 4, 4, 4

[19] A. Kaewcharoen, A. Kaewkhao, Common fixed points for single-valued and multi-valued mappings in G-metric spaces, Int. J. Math. Anal. (Ruse), 5 (2011), 1775-1790. 1, 2, 2.12

[20] S. U. Khan, M. Arshad, A. Hussain, M. Nazam, Two new types of fixed point theorems for F-contraction, J. Adv. Stud. Topol., 7 (2016), 251-260. 1

[21] W. A. Kirk, Some recent results in metric fixed point theory, J. Fixed Point Theory Appl., 2 (2007), 195-207. 1

[22] Z. Mustafa, T. V. An, N. V. Dung, L. T. Quan, Two fixed point theorems for maps on incomplete G-metric spaces, Appl. Math. Sci. (Ruse), 7 (2013), 2271-2281. 1

[23] Z. Mustafa, H. Aydi, E. Karapınar, Generalized Meir-Keeler type contractions on G-metric spaces, Appl. Math. Comput., 219 (2013), 10441-10447.

[24] Z. Mustafa, V. Parvaneh, M. Abbas, J. R. Roshan, Some coincidence point results for generalized $(\psi, \phi)$-weakly contractive mappings in ordered G-metric spaces, Fixed Point Theory Appl., 2013 (2013), 23 pages.

[25] Z. Mustafa, B. Sims, A new approach to generalized metric spaces, J. Nonlinear Convex Anal., 7 (2006), 289-297. 1, 2.1, 2.2, 2.3, 2.4, 2.5, 2.6, 2.7, 2.8

[26] S. B. Nadler, Jr., Multi-valued contraction mappings, Pacific J. Math., 30 (1969), 475-488.

[27] M. Nazam, M. Arshad, On a fixed point theorem with application to integral equations, Int. J. Anal., 2016 (2016), 7 pages. 1

[28] M. Nazam, M. Arshad, M. Abbas, Some fixed point results for dualistic rational contractions, Appl. Gen. Topol., 17 (2016), 199-209. 1

[29] H. Piri, P. Kumam, Some fixed point theorems concerning F-contraction in complete metric spaces, Fixed Point Theory Appl., 2014 (2014), 11 pages.

[30] S. Radenović, B. E. Rhoades, Fixed point theorem for two non-self mappings in cone metric spaces, Comput. Math. Appl., 57 (2009), 1701-1707. 1

[31] K. P. R. Rao, K. B. Lakshmi, Z. Mustafa, A unique common fixed point theorem for six maps in G-metric spaces, Internat. J. Nonlinear Anal. Appl., 3 (2012), 17-23. 1

[32] S. Rezapour, R. Hamlbarani, Some notes on the paper: "Cone metric spaces and fixed point theorems of contractive mappings" [J. Math. Anal. Appl., 332 (2007), 1468-1476] by L.-G. Huang and X. Zhang, J. Math. Anal. Appl., 345 (2008), 719-724. 1

[33] N. A. Secelean, Iterated function systems consisting of F-contractions, Fixed Point Theory Appl., 2013 (2013), 13 pages. 1

[34] N. Tahat, H. Aydi, E. Karapınar, W. Shatanawi, Common fixed points for single-valued and multi-valued maps satisfying a generalized contraction in G-metric spaces, Fixed Point Theory Appl., 2012 (2012), 9 pages. 2.9, 2.10, 4, 4.1, 4, 4.5

[35] D. Wardowski, Fixed points of a new type of contractive mappings in complete metric spaces, Fixed Point Theory Appl., 2012 (2012), 6 pages. 1, 2, 2.13, 2.15 